\title{
Large coordination complexes: synthesis, characterisation and properties
}

\author{
Alan F. WILLIAMS ${ }^{1 *}$ \\ ${ }^{1}$ Department of Inorganic, Analytical and Applied Chemistry, University of Geneva, \\ 30 quai Ernest Ansermet, CH-1211 Geneva 4, Switzerland \\ * Corresponding author.Tel.: +41-22-3796425; fax: +41-22-37 6830; e-mail: Alan.Williams@unige.ch
}

Received April 30, 2009; accepted June 30, 2009; available on-line November 16, 2009

Two aspects of the chemistry of polynuclear complexes are discussed. The first part concerns the application of electrospray mass spectrometry to such complexes. The concept of pseudoisotopic molecules is introduced as two chemical entities which have similar chemical behaviour but which differ in mass and may thus be distinguished in the mass spectrum. It is shown how mixtures of pseudoisotopes readily allow the identification of the nuclearity of complexes. Studies of the exchange of pseudoisotopes show surprising variations in labilty. In favorable cases the evolution of the mass spectrum yields information on the mechanism of the assembly. In the second part we discuss a strategy for the synthesis of large molecular cages, based on the fullerene topology, but using coordinative bonding to assemble the structure.

Coordination chemistry / Supramolecular chemistry / Molecular cages / Electrospray mass spectrometry / Polynuclear complexes

Introduction

It is over a hundred years since Alfred Werner first put forward his theory of coordination complexes. For most of the time that has elapsed since, the attention of coordination chemists has focussed on mononuclear complexes, but in the past twenty years, polynuclear complexes have increasingly dominated this field [1]. Many reasons explain this: polynuclear complexes may show a number of properties impossible for simple mononuclear species, such as metal-metal interactions leading to unusual magnetic properties or remarkable redox chemistry. The aspect that I wish to discuss here is the use of metal ions to assemble ligands into complex molecular structures [2], frequently regarded as a branch of supramolecular chemistry $[3,4]$. Consider the formation of a simple octahedral complex with three bidentate ligands (Fig. 1, left): we would normally say that the ligands complex the metal, but we could just as well say that the metal is locking the ligands into a particular conformation and is organising them in a threedimensional space.
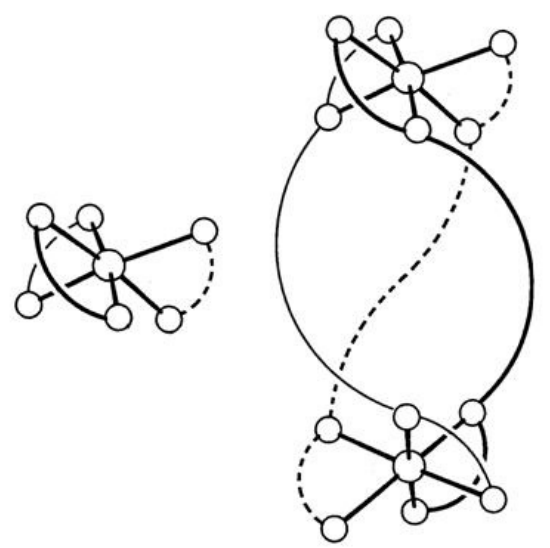

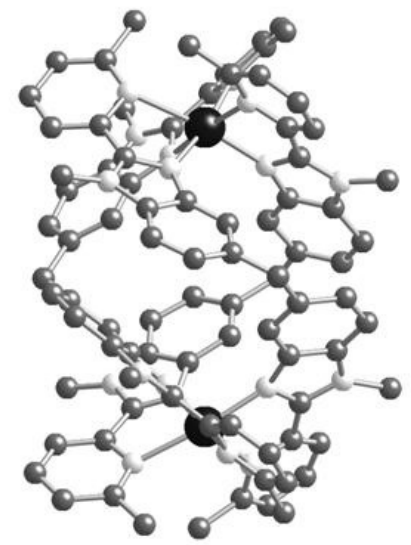

Fig. 1 Left: schematic view of three bidentate ligands complexing one metal ion; middle: extending the bidentate ligand gives a ligand capable of forming a binuclear, triple helical complex; right: the experimental crystal structure of $\left[\mathrm{Co}_{2}(\mathbf{4})_{3}\right]^{4+}$ (see Fig. 8 for structural formula). 
This organisation is more obvious if we now take a slightly more elaborate ligand, with two wellseparated binding sites for a metal ion. Now the ligand can bind two metals, but is organised into a triple helical structure where the three ligands twist round the axis formed by the metal-metal vector [5]. This is shown schematically in the centre of Fig. 1 and the X-ray crystal structure of an actual complex $\left[\mathrm{Co}_{2} \mathrm{~L}_{3}\right]^{4+}$ is shown on the right.

In this simple example two cobalt(II) ions have been used to assemble three ligands to give a large, symmetric structure. This type of reaction has been exploited to produce many elaborate structures in recent years. Fig. 2 shows some examples taken from the work of prominent workers in this field: the double helices of Lehn [6], a box generated by Stang [7], a tetrahedron from Raymond [8] and an octahedron from the Fujita group [9]. These structures are not the fruit of serendipity: they combine careful design of the ligand with thoughtful exploitation of the coordination properties of the metal to form elaborate structures in high yield. Much of the activity in this field has been structural, warranted on the one hand by the aesthetically pleasing structures, and on the other by X-ray crystallography as the ultimate method of characterisation. In this

a)

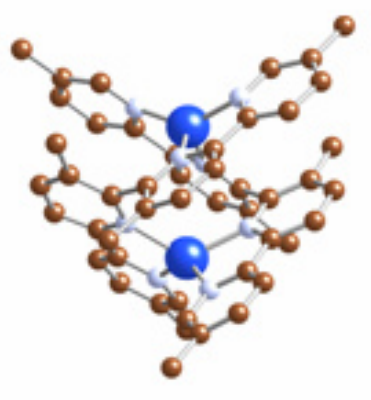

c)

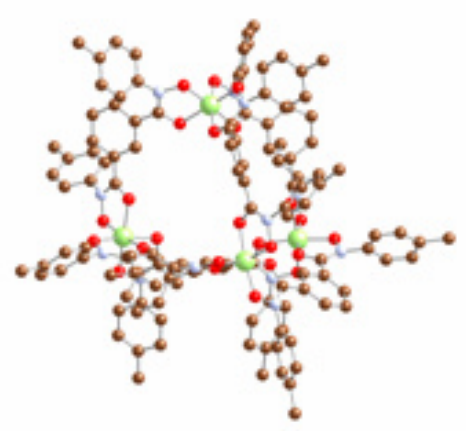

manuscript I wish to concentrate on three other aspects: the use of mass spectrometry to characterise these complexes, its extension to study the kinetics of self-assembled systems, and finally a preliminary report on a synthetic approach to large spherical capsules. The systems which I will discuss in connection with characterisation and kinetics are the triple helices of Fig. 1, the cubane complexes of transition metals, and the polyoxometallates with the Keggin structure shown in Fig. 3.

\section{Characterising polynuclear complexes: the PIMMS method}

The synthesis of polynuclear complexes with molecular weights of several thousand Daltons has presented a challenge for the characterisation of the complexes. The arrival of electrospray mass spectrometry (ES-MS) as a generally available technique some 10-15 years ago was a great help to coordination chemists since it meant direct study of charged complexes in solution at experimentally useful concentrations of $10^{-4}$ to $10^{-5} \mathrm{M}$ became possible. Although the interpretation of the spectra is not always as straightforward as one would like, particularly regarding the correlation of intensities and b)

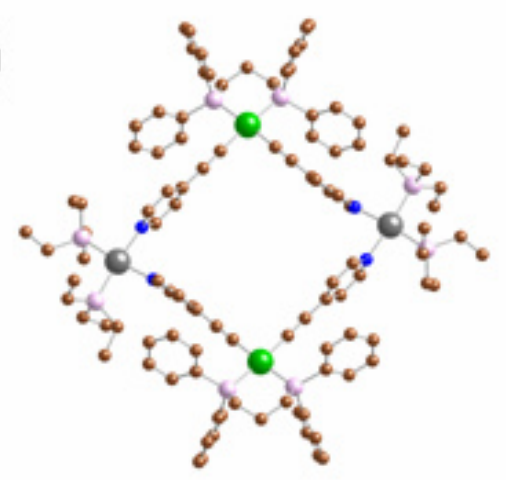

d)

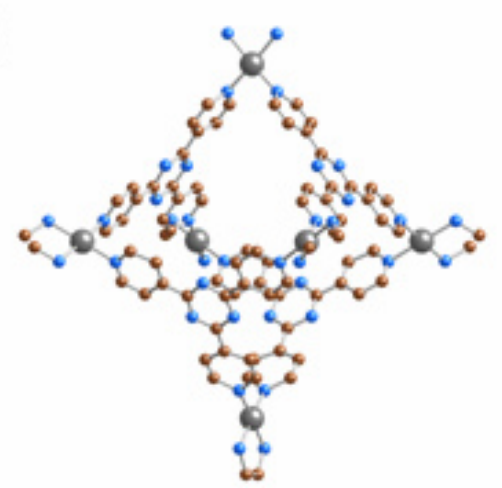

Fig. 2 Some typical polynuclear structures: a) $\left[\mathrm{Cu}_{2} \mathrm{~L}_{2}\right]$ double helix [10]; b) $\mathrm{Pd}_{2} \mathrm{Pt}_{2}$ box [7]; c) $\left[\mathrm{Ga}_{4} \mathrm{~L}_{6}\right]$ tetrahedron [8]; d) $\left[\mathrm{Pd}_{6} \mathrm{~L}_{4}\right]$ octahedron [9]. 


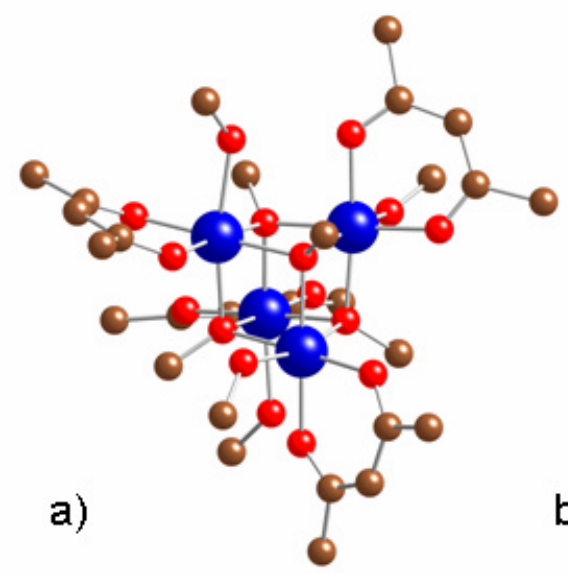

b)

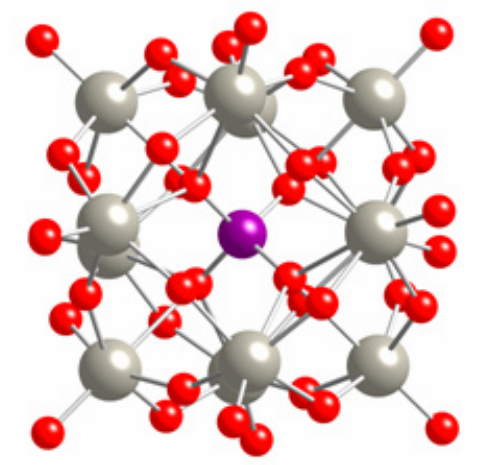

Fig. 3 a) a typical cubane complex with a $\mathrm{Co}_{4} \mathrm{O}_{4}$ core; b) the Keggin structure $\left[\mathrm{EW}_{12} \mathrm{O}_{40}\right]^{\mathrm{n}-}$.

concentrations, it has become an indispensable tool [11-13]. One problem that appears frequently however is the distinction between species with different values of $n$ in complexes of type $\left[\mathrm{M}_{\mathrm{p}} \mathrm{L}_{\mathrm{q}}{ }^{\mathrm{z}}\right]_{n}$ : complexes with different values of $n$ will all give peaks at the same $\mathrm{m} / \mathrm{z}$ value. Isotopic splittings may help to distinguish the value of $n$, but the distribution of isotopes in nature is not always favourable. Some elements have only one isotope, others such as molybdenum and tungsten have so many that the peaks become very complicated for high nuclearity. If the total charge $n \times z$ is high the splitting of peaks becomes smaller and one may have difficulty resolving the different isotopic peaks. When ion pair formation is observed this can allow identification of the charge, and consequently of the value of $n \times z$, but this is not always the case. If one were to imagine an ideal world, one would like a choice of isotopes, preferably showing a large mass difference. The rules of nuclear physics preclude this, but we can do something quite similar. Consider the two ligands $\mathbf{1}$ and 2 in Fig. 4:<smiles>Cn1c([C@H](O)[C@H](O)c2nc3ccccc3n2C)nc2ccccc21</smiles>

1<smiles>Cc1ccc2nc([C@@H](O)[C@H](O)c3nc4ccc(C)cc4n3C)n(C)c2c1</smiles>

2

Fig. 4 Structural formulae of ligands $\mathbf{1}$ and 2.
They are clearly identical as far as their coordination properties are concerned, differing only in the presence of two methyl groups remote from the coordination centre. Their coordination properties would be expected to be identical, the only difference being their molecular weight, 28 units greater for $\mathbf{2}$ than for 1. We will call these two ligands pseudoisotopic molecules, defined as two species which, within a given chemical system, are chemically identical, but have different masses. The limitation as to one system is important: for example, we might expect the two ligands to show identical complexion behaviour in solution, their crystal packing is likely to be different. Both $\mathbf{1}$ and $\mathbf{2}$ can form polynuclear complexes such as the cubane $\left[\mathrm{Co}_{4}(\mathbf{1}-\mathrm{H})_{4}\right]^{4+}$ where one alcohol function is deprotonated to bridge metal ions, as shown in Fig. 5.

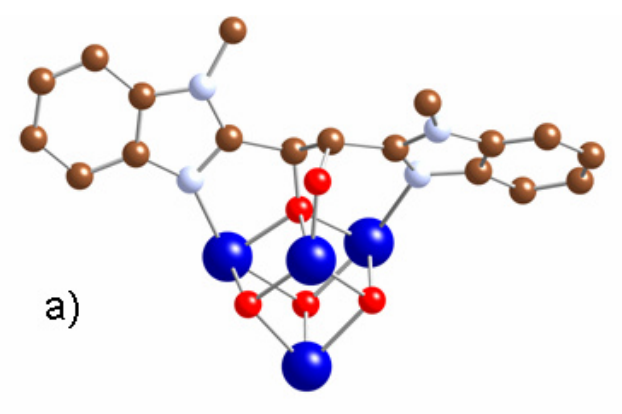

b)

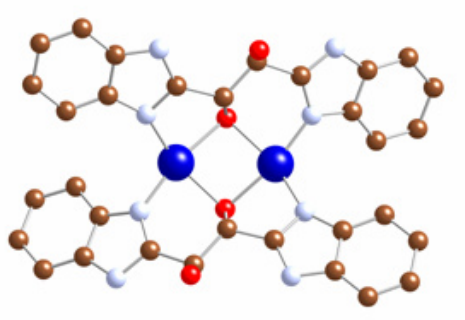

Fig. 5 a) The $\mathrm{Co}_{4} \mathrm{O}_{4}$ core of a cubane showing the binding of ligand $1 ; b)$ modelled structure for a possible $\left[\mathrm{Co}_{2}(\mathbf{1}-\mathrm{H})_{2}\right]$ complex. 
Table 1 Mass spectra predicted for $\left[\mathrm{Co}_{\mathrm{p}} \mathrm{L}_{\mathrm{p}}-\mathrm{nH}\right]^{\mathrm{z+}}$ where $\mathrm{L}$ is an equimolar mixture of $\mathbf{1}$ and $\mathbf{2}$.

\begin{tabular}{c|c|c}
\hline Species & Predicted peaks & Intensity \\
\hline$\left[\mathrm{Co}_{2} \mathrm{~L}_{2}-2 \mathrm{H}\right]^{2+}$ & $352.5,366.5,380.5$ & $1: 2: 1$ \\
{$\left[\mathrm{Co}_{2} \mathrm{~L}_{2}-3 \mathrm{H}\right]^{+}$} & $703.5,731.5,759.5$ & $1: 2: 1$ \\
{$\left[\mathrm{Co}_{4} \mathrm{~L}_{2}-6 \mathrm{H}\right]^{2+}$} & $703.5,717.5,731.5,745.5,759.5$ & $1: 4: 6: 4: 1$ \\
\hline
\end{tabular}

However they could equally form dimers $\left[\mathrm{Co}_{2}(\mathbf{1}-\mathrm{H})_{2}\right]^{2+}$, and both species will show peaks at $\mathrm{m} / \mathrm{z}$ 703 in the mass spectrum. If we repeat the experiment using ligand 2 the two major peaks at $\mathrm{m} / \mathrm{z} 556.3$ and 703.5 shift to 598.7 and 759.5 , or 42 and 56 mass units respectively. Since the mass difference between $\mathbf{1}$ and $\mathbf{2}$ is 28 , the first peak must correspond to $\left[\mathrm{Co}_{4} \mathrm{~L}_{3}-6 \mathrm{H}\right]^{2+}$ while the second could be either $\left[\mathrm{Co}_{4} \mathrm{~L}_{4}-6 \mathrm{H}\right]^{2+}$ or $\left[\mathrm{Co}_{2} \mathrm{~L}_{2}-3 \mathrm{H}\right]^{+}$. A clearer experiment is to form the complex from an equimolar mixture of $\mathbf{1}$ and 2. The dinuclear complex will give a triplet signal due to the three species $\left[\mathrm{Co}_{2}(\mathbf{1})_{n}(\mathbf{2})_{2-n}-3 \mathrm{H}\right]^{+}(n=0-2)$ while the tetranuclear will give a quintuplet due to $\left[\mathrm{Co}_{4}(\mathbf{1})_{n}(\mathbf{2})_{4-n}-6 \mathrm{H}\right]^{2+}(n=$ $0-4)$. The multiplicity of the signal thus indicates the number of ligands present in the ion while the separation of the peaks is equal to the mass difference between the pseudoisotopic molecules divided by the charge. Table 1 gives the spectra predicted for the different species. Fig. 6 shows the spectrum for an equal mixture of $\mathbf{1}$ and $\mathbf{2}$. The peak centred at $\mathrm{m} / \mathrm{z}=$ 731 is a quintuplet, clearly establishing the presence of a tetraligand species, and the peak separation of 14 indicates $\mathrm{a}+2$ species. The triplet centred at $\mathrm{m} / \mathrm{z}, 366$ must contain two ligands and is thus identified as $\left[\mathrm{Co}_{2} \mathrm{~L}_{2}-2 \mathrm{H}\right]^{2+}$.

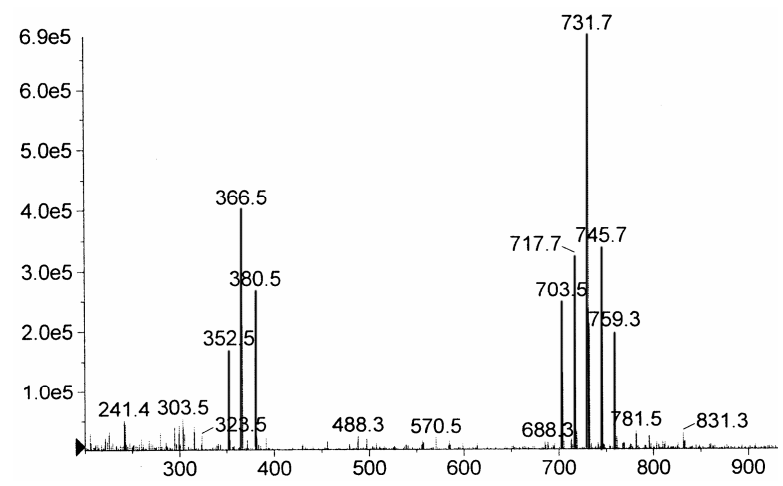

Fig. 6 ES-MS spectrum of an mixture of 2 equivalents of cobalt(II), one equivalent of $\mathbf{1}$, one equivalent of $\mathbf{2}$, and two equivalents of base.

It is often stated, quite correctly, that the intensities of peaks in the mass spectrum may not correlate directly with the concentrations present in solution. This is generally true, but we have found that when comparing pseudoisotopic peaks the intensities do indeed display the expected ratio. This is perhaps not surprising since we are comparing ions which are very similar, having the same charge and differing only in substituents on the periphery of the molecule. Moreover the method is self-verifying: if $\mathbf{1}$ and $\mathbf{2}$ do indeed have different properties, then we will no longer see a statistical distribution of peaks. In Fig. 6 the quintuplet peak is quite symmetric, which is only possible if $\mathbf{1}$ and $\mathbf{2}$ are truly pseudoisotopic. The observant reader may note that the intensity distribution is not the $1: 4: 6: 4: 1$ that one would expect from the binomial distribution. Peaks 1, 3, 5 are rather too intense. This may be explained if the ions $\left[\mathrm{Co}_{2}(\mathbf{1})_{n}(\mathbf{2})_{2-n}-3 \mathrm{H}\right]^{+}$and $\left[\mathrm{Co}_{4}(\mathbf{1})_{n}(\mathbf{2})_{4-n}-6 \mathrm{H}\right]^{2+}$ are both present, since the dinuclear complex would contribute to these peaks. Only the tetranuclear species will contribute to peaks 2 and 4 . The formation of the dinuclear species as a decomposition product was confirmed by measuring the spectrum again at a higher collision energy, where more of the dinuclear species is formed and consequently peaks 1 , 3 and 5 increase still more in intensity [14]. The definition given above is not limited to organic substitutions. Different lanthanide ions have been used as mass spectrometric markers [15], and we give here a second example from heteropolymetallate chemistry. The heteropolymetallates with the Keggin structure $\left[E M_{12} \mathrm{O}_{40}\right]^{n-}$ have been known for over 150 years for $M=\mathrm{W}$ or Mo with a wide variety of heteroelements $E$. Students are taught that $4 \mathrm{~d}$ and $5 \mathrm{~d}$ elements have very similar chemistry, and indeed at the beginning of the series their separation is not trivial. So $\mathrm{MoO}_{4}{ }^{2-}$ and $\mathrm{WO}_{4}{ }^{2-}$ might be expected to behave as pseudoisotopic ions, and indeed Howarth and co-workers showed some years ago that tungstate and molybdate mix in heteropolymetallates [16]. Fig. 7 shows the ES-MS spectrum of a solution of $\left[\mathrm{PW}_{12} \mathrm{O}_{40}\right]^{3-}$ where one sixth of the tungstate was replaced by molybdate. As can be seen the single peak observed for pure $\left[\mathrm{PW}_{12} \mathrm{O}_{40}\right]^{3-}$ becomes a multiplet, with separations of 30 mass units, one third of the mass difference between tungsten and molybdenum, as expected for a 3- anion. The intensities are in agreement with a calculation based on the binomial distribution. The use of pseudoisotopic molecules is not unprecedented, and several examples using derivatised organic molecules are known in the literature [17-20], although we believe that we are the first to formalise the approach. We refer to it as PseudoIsotopic Molecule Mass Spectrometry, more easily remembered as PIMMS. The advantages of using PIMMS are easy attribution of peaks and identification of the nuclearity of species. Pseudoisotopes are often more readily obtained (by simple synthetic modification) than true isotopes, and 


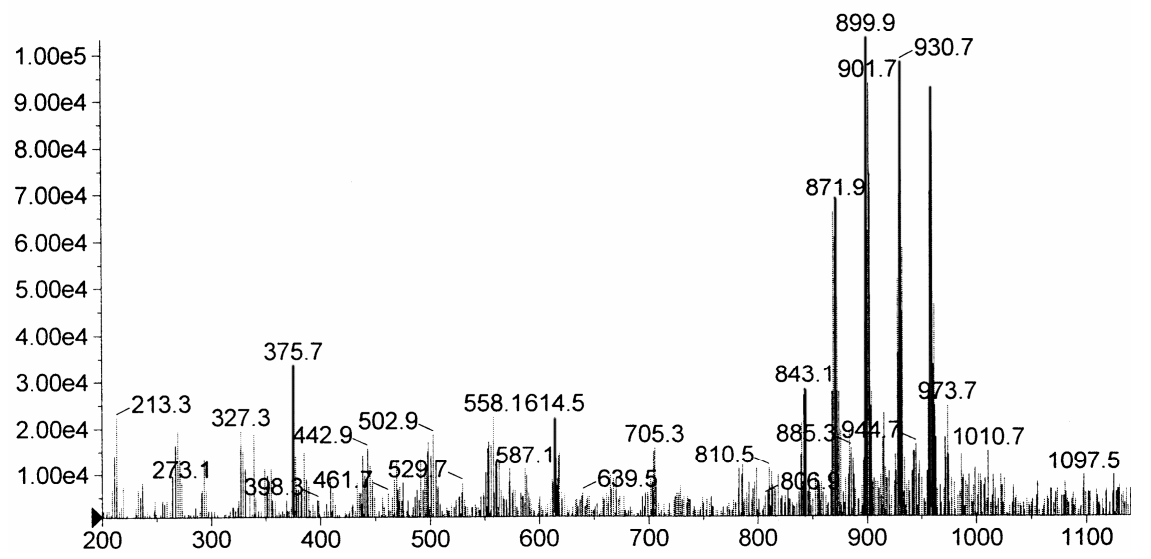

Fig. 7 ESMS spectrum of $\left[\mathrm{PW}_{12} \mathrm{O}_{40}\right]^{3-}$ containing $16.6 \%$ molybdate, showing the statistical distribution of molybdate ions.

show much greater mass differences. The mixture of pseudoisotopes can be varied as the chemist pleases. Finally, any deviation from pseudoisotopic behaviour may be detected by the non-statistical distribution of the peak intensities.

\section{Investigating kinetics with PIMMS}

Studying isotope exchange has been a major source of information on reaction mechanisms. It is equally possible to use pseudoisotopes to investigate mechanisms. In this section we will illustrate this with some examples from our own work on polynuclear coordination compounds. It is usually stated that self-assembly reactions are rapid, reversible and proceed to the thermodynamically most favourable structure. This is sometimes interpreted as implying that all reactions of such species are rapid, but the data available for these systems are limited and tend to contradict it. Our first observation, many years ago, concerned the racemisation of the cobalt(II) triple helicate $\left[\mathrm{Co}_{2} \mathbf{4}_{3}\right]^{4+}$ shown in Fig. 1 and 8.

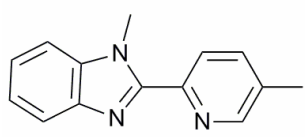

3

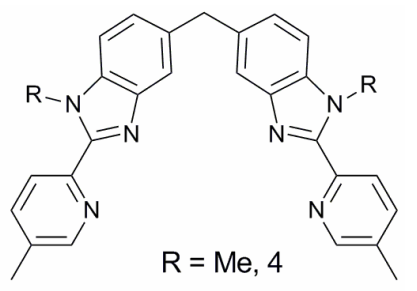

$\mathrm{R}=\mathrm{Et}, 5$
Fig. 8 Structural formulae of ligands $3-5$.

Although the cobalt(II) ion is generally considered as labile, with exchange taking place on the stopped flow timescale as evidenced by the rapid exchange of diastereomers of $\left[\mathrm{Co}(3)_{3}\right]^{2+}[21]$, the triple helicate $\left[\mathrm{Co}_{2}(4)_{3}\right]^{4+}$ showed racemisation six orders of magnitude slower [22]. This remarkable difference could be explained by a series of experiments using ligand 4 and its pseudoisotopic molecule 5 [21]. Mixture of solutions of $\left[\mathrm{Co}_{2}(\mathbf{4})_{3}\right]^{4+}$ and $\left[\mathrm{Co}_{2}(\mathbf{5})_{3}\right]^{4+}$ in acetonitrile gave very clean ES-MS spectra and showed slow scrambling of the ligands $\mathbf{4}$ and $\mathbf{5}$ when followed by mass spectrometry, leading after several hours to the expected statistical mixtures of compounds. On mixing $\left[\mathrm{Co}_{2}(\mathbf{5})_{3}\right]^{4+}$ with free ligand $\mathbf{4}$, the peak in the mass spectrum due to $\left[\mathrm{Co}_{2}(\mathbf{5})_{3}\right]^{4+}$ disappeared over a period of 100 minutes, while peaks due to complexes containing ligand $\mathbf{4}$ appeared. Surprisingly, the peak due to $\left[\mathrm{Co}_{2}(4)_{3}\right]^{4+}$ grew much faster than the others, suggesting, rather paradoxically, that the exchange of all three ligands was faster than the exchange of only one or two. The paradox could be resolved by the mechanism shown in Fig. 9, in which the complex slowly dissociates a metal ion to give $\mathrm{CoL}_{3}$ and Co. This involves breaking six metalligand bonds, and will consequently be slow. The second metal holds the three strands of the ligand close to the first, and the stepwise dissociation of the chelating units is harder. In the second step, the free Co produced by the dissociation will be complexed rapidly by free ligand 4 . The two mononuclear complexes thus produced can both capture a metal ion to give either $\left[\mathrm{Co}_{2}(\mathbf{5})_{3}\right]^{4+}$ or $\left[\mathrm{Co}_{2}(\mathbf{4})_{3}\right]^{4+}$. In the first case the net reaction is nil, but in the second, the fully substituted product $\left[\mathrm{Co}_{2}(\mathbf{4})_{3}\right]^{4+}$ is formed. It is only after the reaction has proceeded for some time that the amount of $\mathbf{5}$ liberated will be sufficient to allow formation of mixed ligand species.

The inertness of the triple helicates may be reasonably attributed to the obligation to break several bonds before an exchange can take place. A similar effect is seen with the cubanes formed by ligands $\mathbf{1}$ and 2 (Fig. 5). When solutions of the cubanes $\left[\mathrm{Co}_{4}(\mathbf{1}-\mathrm{H})_{4}\right]^{2+}$ and $\left[\mathrm{Co}_{4}(2-\mathrm{H})_{4}\right]^{2+}$ are mixed only slight $(<10 \%)$ exchange is observed after several days, an astonishing result for the formally labile cobalt(II) ion. If the cubane $\left[\mathrm{Mn}_{4}(\mathbf{1}-\mathrm{H})_{4}\right]^{2+}$ is reacted with free cobalt(II) which forms a more stable cubane, only 


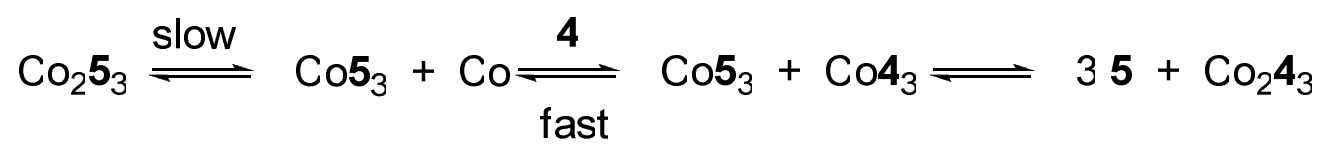

Fig. 9 Mechanism for ligand exchange in a triple helicate.

partial substitution is observed after three hours, and this shows formation of $\left[\mathrm{Co}_{4}(\mathbf{1}-\mathrm{H})_{4}\right]^{2+}$ rather than mixed metal species, excluding a stepwise exchange of metals and implying that the mechanism involves complete decomposition and recomposition [14].

A final example concerns the polymetallates $\left[E M_{12} \mathrm{O}_{40}\right]^{n-}, M=\mathrm{Mo}, \mathrm{W}, E=\mathrm{P}$, As, Si. Our initial belief was that these species, involving a metal(VI) ion which will have considerable covalent character, would show rather slow kinetics. On mixing $\left[\mathrm{PMo}_{12} \mathrm{O}_{40}\right]^{3-}$ and $\left[\mathrm{PW}_{12} \mathrm{O}_{40}\right]^{3-}$ in acid solution we were surprised to see rapid exchange after only 5 seconds, with complete exchange within one hour (Fig. 10).

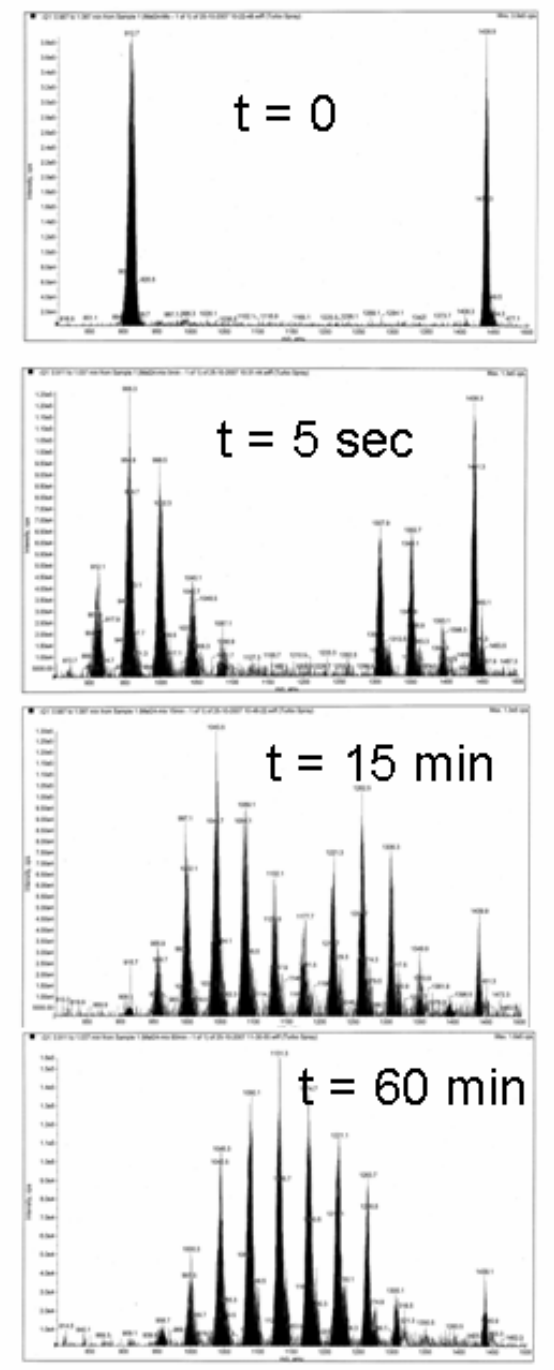

Fig. 10 Changes in intensities of the peaks in the ES-MS spectrum due to $\left[\mathrm{HPMo}_{n} \mathrm{~W}_{12-n} \mathrm{O}_{40}\right]^{2-}$ on mixing $\left[\mathrm{PMo}_{12} \mathrm{O}_{40}\right]^{3-}$ and $\left[\mathrm{PW}_{12} \mathrm{O}_{40}\right]^{3-}$ in acid solution.
In this case the way in which the spectrum changes is extremely informative about the mechanism. The initially formed species are those in which only one or two metal ions are changed; species in which there has been statistical mixing of the metals are observed only at the end of the reaction. This argues in favour of a stepwise exchange of metals as shown in Fig. 11:

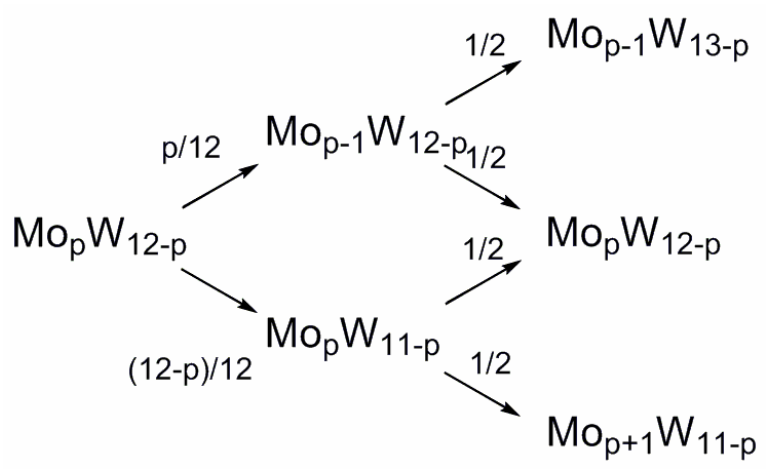

Fig. 11 Mechanism for metal exchange in $\left[\mathrm{PM}_{12} \mathrm{O}_{40}\right]^{3-}$.

If we assume a purely statistical model, the probability of a given complex $\mathrm{Mo}_{p} \mathrm{~W}_{12-p}$ losing a molybdenum is $p / 12$, and of losing a tungsten $(12-p) / 12$. Since there is an equimolar amount of tungsten and molybdenum in the solution, there is an equal probability of the resulting complex capturing a molybdenum or a tungsten. It is a trivial matter to simulate the development of the mass spectrum using this model, and one obtains a pattern very similar to that seen in Fig. 10. Such a mechanism is chemically very reasonable since the lacunary species $\left[\mathrm{PM}_{11} \mathrm{O}_{39}\right]^{7-}$ is known to be formed at slightly higher $\mathrm{pH}$, and is thus quite accessible. A rapid exchange is therefore not quite so surprising. The related arsenometallate also shows rapid exchange, but no exchange at all is seen for the silicotungstate $\left[\mathrm{SiW}_{12} \mathrm{O}_{40}\right]^{4-}$ under these conditions [23]. This may be related to the stronger interaction between the silicate ion and the metallate cage as evidenced by the silicate-tungsten bond length and the quadrupole coupling at the tungsten nucleus [24].

The three examples given here show that substitution in these polynuclear systems can show a remarkable kinetic range. This fact does not seem to be generally appreciated, but offers potentially the possibility of inorganic synthesis under kinetic control, hitherto the reserve of organic chemistry. Mass spectrometry coupled with pseudoisotopic 
exchange offers a simple and effective means of studying these reactions.

\section{A synthetic approach to self-assembled spheres}

The final subject I wish to discuss is a synthetic problem. Can we use the assembly of polynuclear complexes from suitably chosen metals and ligands to create new and previously inaccessible structures? The example I would like to discuss is the assembly of spherical units, or molecular capsules. This offers not only an aesthetic challenge, as shown by the popularity of the spherical molecule $\mathrm{C}_{60}$ as an illustration for chemistry books, but also potential applications as 'molecular flasks' for encapsulating other molecules or creating a constrained volume for chemical reactions $[25,26]$. We may also regard the synthesis of closed spherical molecules as a chemical approach to the question of how nature can generate quite precisely closed volumes inside the cell.

Buckminsterfullerene, $\mathrm{C}_{60}$, is a highly symmetric molecule. Formally it is self-assembled from $60 \mathrm{sp}^{2}$ hybridised carbon atoms, but this is clearly not a feasible route for a high yield synthesis, since $\mathrm{sp}^{2}$ carbon atoms more usually assemble to produce planar, extended sheets of graphite. So why is spherical $\mathrm{C}_{60}$ formed? The secret is in the inclusion of pentagons in the structure. It is well known that pentagonal tiles cannot be used to cover a planar surface. If we try to link pentagons by their vertices, as shown in Fig. 12, then it is not possible, in a planar structure, for all bonds to have the same length. If we force the bonds shown as dashed lines to have the same length as those shown as solid lines, then the structure will naturally curve to a hemispherical form. The curvature is thus induced by the geometry.

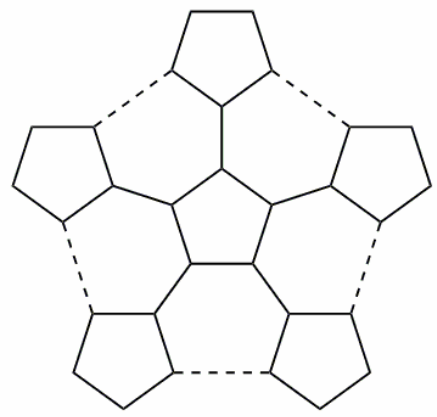

Fig. 12 Linking pentagons: if the dashed bonds are shrunk to the same length as the other bonds, the structure must curve into a bowl shape.

Following this reasoning, we thought that if we took a ligand with five binding sites in a pentagonal arrangement, and attempted to link them by metal ions, a fullerene like structure should result. Our first choice of ligand was the pentacyanocyclopentadienyl anion, 6, which was reported some years ago by Webster [27] (Fig. 13).

The cyanide functions are good donors for ions such as copper(I) and silver(I) which can show linear coordination. Thus copper or silver ions could link anions $\mathbf{6}$ to give a fullerene-like structure. A computer model of the structure is shown in Fig. 14.

6

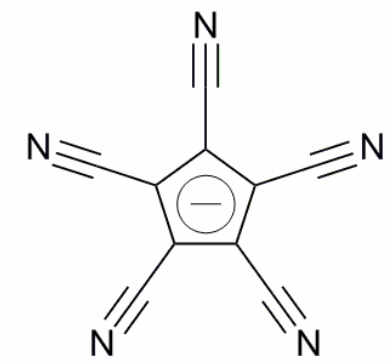

Fig. 13 Structural formula of the pentacyanocyclopentadienide anion, 6.
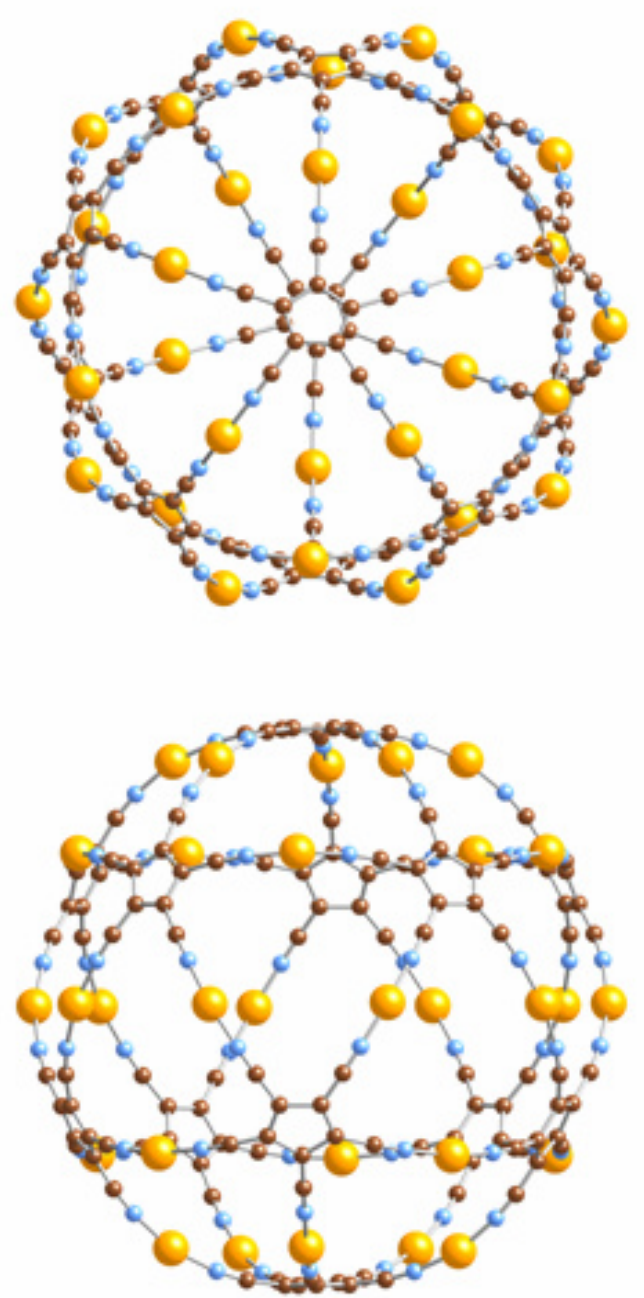

Fig. 14 Computer Model of $\left[\mathrm{Cu}_{30}(\mathbf{6})_{12}\right]^{18+}$ looking down $\mathrm{a} \mathrm{C}_{5}$ axis (top) and perpendicular to this axis (bottom). 
The model does not require any severe distortion of angles or bond lengths. This therefore seemed a good system to begin with, but no reaction was observed with copper(I), and with silver(I) a dark brown precipitate of composition $\mathrm{Ag}\left[\mathrm{C}_{5}(\mathrm{CN})_{5}\right]$ was obtained. The structure of this precipitate could be solved by X-ray powder methods, and showed a polymeric structure in which only three of the cyanide functions coordinate the silver (Fig. 15) [28].

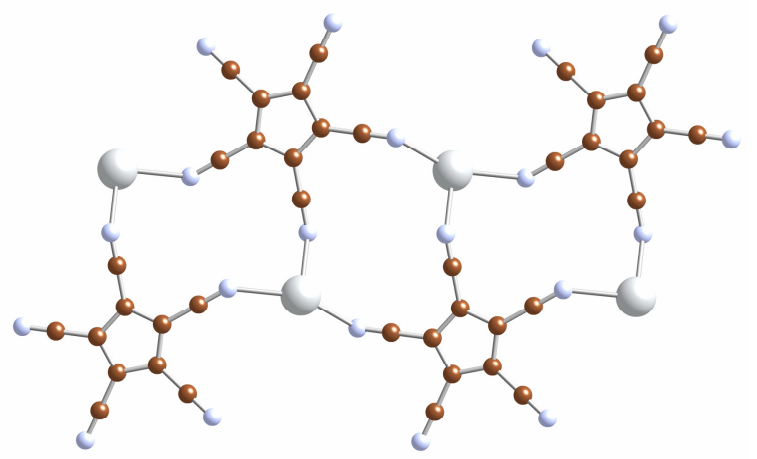

Fig. 15 The polymeric structure of $\operatorname{Ag}(6)$.

After this disappointing start we decided to replace the cyanide functions by 4-pyridyl units to give 7 (Fig. 16). Although we succeeded in the synthesis of $7 \mathrm{H}$, it was extremely sensitive to oxidation, and we therefore sought to stabilise it by complexation of a metal to the cyclopentadienide fragment. This could be achieved by starting from a phosphinoferrocene compound $\mathbf{8}$ using a palladium catalysed pyridylation according to the method of Hartwig [29] followed by oxidation of the phosphine (to avoid competing complexation reactions) to give the ligand $\mathbf{9}$ whose crystal structure is shown in Fig. 17.

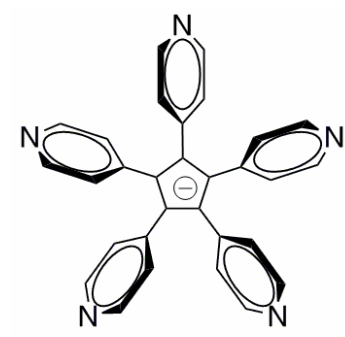

7

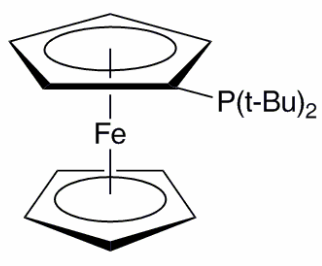

8

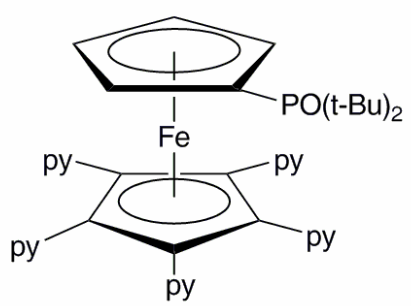

9

Fig. 16 Structural formulae of substituted ferrocenes $7-9$.

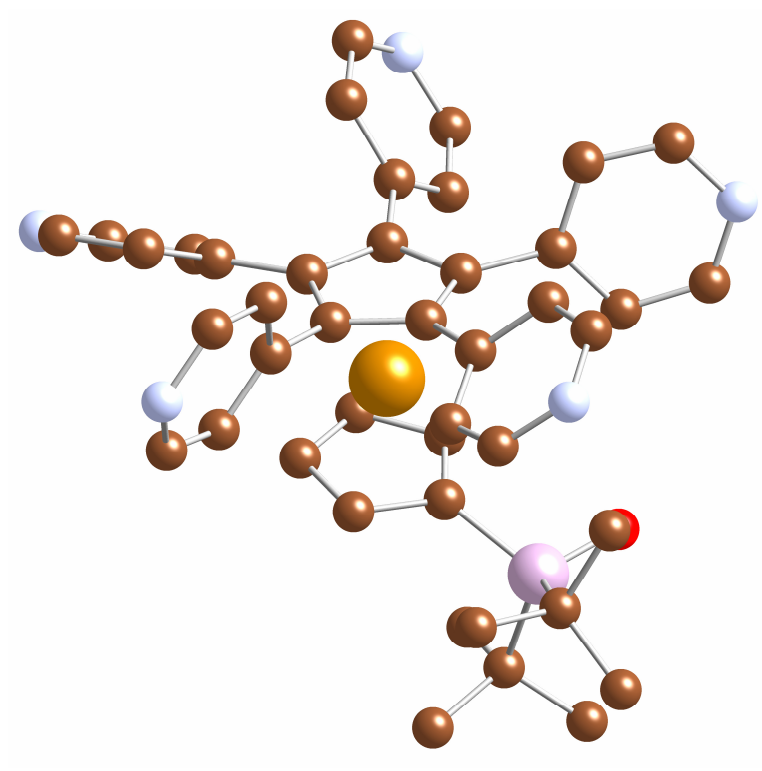

Fig. 17 Crystal structure of ligand 9.

Ligand 9 reacts with copper(I) as shown by the shift of the pyridyl signals in the ${ }^{1} \mathrm{H}$ NMR spectrum. An end point is observed at 2.5 equivalents of metal per ligand which is the ratio to be expected if all five pyridyl sites are occupied by bridging metal ions. The NMR spectrum remains highly symmetrical. A computer model of the proposed structure $\left[\mathrm{Cu}_{30}(\mathbf{9})_{12}\right]^{30+}$ suggests a sphere of approximate diameter $30 \AA$, and in accord with this the diffusion coefficient of the complex as measured by NMR is three times smaller than that of the free ligand. Application of the Stokes-Einstein equation gives a hydrodynamic radius of $16 \AA$, in good agreement with the model structure. Preliminary light scattering results also agree with this radius [30]. We therefore consider that it is reasonable to believe that a symmetrical cage $\left[\mathrm{Cu}_{30}(\mathbf{9})_{12}\right]^{30+}$ analogous to the cage $\left[\mathrm{Cu}_{30}(\mathbf{6})_{12}\right]^{18+}$ of Fig. 14 is formed. Silver(I) shows very similar behaviour.

Two features seem worthy of emphasis in this work: firstly, we will need to develop new analytical techniques to fully characterise species with molecular weights greater than 10'000 Dalton, and secondly that the construction of this large spheroidal cage is based on a purely geometric principle, in which coordination chemistry returns to ideas already established by the ancient Greeks.

\section{Acknowledgements}

I am most grateful to the Swiss National Science Foundation for their constant support of my research for many years. I acknowledge the as yet unpublished work of my collaborators Drs Sarah Clifford, Mirka Bergamo, and Carlos da Silva, Alexandra Spyratou, 
Mathieu Tissot, Xavier Melich and Grégoire Bonvin. The contents of this manuscript were initially presented at the $17^{\text {th }}$ Ukrainian Conference on Inorganic Chemistry in Lviv in September 2008, and the author would like to thank the Ukrainian Academy of Sciences and the Ivan Franko National University of Lviv for their invitation and their hospitality. I thank Professor Oliver Wenger for comments on a first version of this manuscript.

\section{References}

[1] R.E.P. Winpenny, Adv. Inorg. Chem. 52 (2001) 1.

[2] G.F. Swiegers, T.J. Malefetse, Chem. Rev. 100 (2000) 3483.

[3] J.-M. Lehn, Supramolecular Chemistry, VCH, 1995.

[4] J.W. Steed, J.L. Atwood, Supramolecular Chemistry, J. Wiley \& Sons Ltd, 2000.

[5] A.F. Williams, C. Piguet, G. Bernardinelli, Angew. Chem. Int. Ed. 30 (1991) 1490.

[6] J.-M. Lehn, A. Rigault, J. Siegel, J. Harrowfield, B. Chevrier, D. Moras, Proc. Nat. Acad. Sci. U.S.A. 84 (1987) 2565.

[7] J.A. Whiteford, C.V. Lu, P.J. Stang, J. Am. Chem. Soc. 119 (1997) 2524.

[8] T.N. Beissel, R.E. Powers, K.N. Raymond, Angew. Chem. Int. Ed. 35 (1996) 1084.

[9] M. Fujita, D. Oguro, M. Miyazawa, H. Oka, K. Yamaguchi, K. Ogura, Nature 378 (1995) 469.

[10] J.-M. Lehn, J.-P. Sauvage, J. Simon, R. Ziessel, Nouv. J. Chim. 7 (1983) 413.

[11] M. Kogej, C.A. Schalley, In: C.A. Schalley (Ed.), Analytical Methods in Supramolecular Chemistry, Wiley VCH, Weinheim, 2007, p. 104.

[12] W.W. Henderson, B.K. Nicholson, L.J. McCaffey, Polyhedron 17 (1998) 4291.

[13] R. Colton, A. D'Agostino, J.C. Traeger, Mass Spectrom. Rev. 14 (1995) 79.
[14] A. Spyratou, S. Clifford, X. Melich, A.F. Williams, 2009 (unpublished results).

[15] P.A. Whetstone, N.G. Butlin, T.M. Corneille, C.F. Meares, Bioconjugate Chem. 15 (2004) 3.

[16] M.J. Deery, O.W. Howarth, K.R. Jennings, J. Chem. Soc., Dalton Trans. (1997) 4783.

[17] S.J. Rowan, P.A. Brady, J.K.M. Sanders, Angew. Chem. Int. Ed. 35 (1996) 2143.

[18] G.R.L. Cousins, S.-A. Poulsen, J.K.M. Sanders, Chem. Commun. (1999) 1575.

[19] K.S. Chichak, S.J. Cantrill, J.F. Stoddart, Chem. Commun. (2005) 3391.

[20] M. Albrecht, S. Mirtschin, M. de Groot, I. Janser, J. Runsink, G. Raabe, M. Kogej, C.A. Schalley, R. Fröhlich, J. Am. Chem. Soc. 127 (2005) 10371.

[21] L.J. Charbonnière, A.F. Williams, U. Frey, A.E. Merbach, P. Kamalaprija, O. Schaad, J. Am. Chem. Soc. 119 (1997) 2488.

[22] L.J. Charbonnière, M.-F. Gilet, K. Bernauer, A.F. Williams, J. Chem. Soc., Chem. Commun. (1996) 39.

[23] G. Bonvin, M. Tissot, X. Melich, A.F. Williams, 2009 (unpublished results).

[24] C.G. Bochet, T. Draper, B. Bocquet, M.T. Pope, A.F. Williams, Dalton Trans. (2009) 5127.

[25] D. Fiedler, D. Pagliero, J.L. Brumaghim, R.G. Bergman, K.N. Raymond, Inorg. Chem. 43 (2004) 846.

[26] M. Yoshizawa, Y. Takeyama, T. Kusukawa, M. Fujita, Angew. Chem. Int. Ed. 41 (2002) 1347.

[27] O.W. Webster, J. Am. Chem. Soc. 88 (1966) 4055.

[28] C. da Silva, M. Bergamo, A.F. Williams, R. Cerny, P.-Y. Morgantini (unpublished observations).

[29] N. Kataoka, Q. Shelby, J.P. Stambuli, J.F. Hartwig, J. Org. Chem. 67 (2002) 5553.

[30] O. Oms, T. Jarrosson, L.H. Tong, A. Vaccaro, G. Bernardinelli, A.F. Williams, Chem. Eur. J., 16 (2009) 5012. 